\title{
Lawaai, stank \\ en lichtvervuiling \\ in \\ in Vlaanderen
}

AUTEUR Gunther Van Broeck

\section{Met 67 duizend kilometer verlichte wegen en evenveel varkens als inwoners staat de leefbaarheid van het relatief kleine Vlaanderen sterk onder druk: lawaaiover- last, stank en lichtvervuiling zijn de gevolgen.}

De Vlaamse overheid voert een beleid dat gericht is om deze vormen van overlast onder controle te krijgen. Om dit beleid te evalueren en tendensen op te sporen wordt sinds 2001 op regelmatige basis gepeild naar de tevredenheid van de burgers met betrekking tot hun leefomgeving. Vooral geluids-, geur- en lichthinder worden in Schriftelijke Leefomgevingsonderzoeken (SLO) onder de loep genomen. Tot nu toe werd deze grootschalige enquêtering drie keer uitgevoerd: in 2001 (SLO0) bij ruim 3200 mensen, en in 2004 (SLO1) en 2008 (SLO2) bij ruim vijfduizend mensen. Hierbij werd telkens de situatie in respectievelijk 2000, 2003 en 2007 geëvalueerd. Een volgende enquêtering (SLO3), waarin de situatie van 2012 zal worden geëvalueerd, wordt voorzien in 2013. Met de resultaten is het mogelijk de evolutie op vlak van milieuhinder te beoordelen. Dit kan leiden tot een bevestiging, bijsturing of versterking van het gevoerde beleid.

In dit artikel worden de resultaten van SLO enquêtes kort beschreven, geïnterpreteerd en onderling vergeleken. We kijken ook even over het muurtje bij de buren in Nederland, waar min of meer vergelijkbaar cijfermateriaal voorhanden is.

Met de SLO enquêtes wordt een representatief staal van de Vlaamse bevolking bevraagd. De ondervraagden zijn ouder dan zestien jaar en geografisch evenredig verspreid over het grondgebied. Mogelijke respondenten worden in eerste instantie telefonisch gescreend zodat de representativiteit van de uiteindelijke steekproef kan worden aangestuurd. De enquêtering zelf gebeurt schriftelijk door middel van een vragenlijst van een achttal pagina's. De algemene respons bedraagt steeds meer dan vijftig procent van het aantal personen die telefonisch hebben bevestigd te willen deelnemen aan het onderzoek.

Algemeen blijkt dat zeven op de tien Vlamingen tevreden tot zeer tevreden zijn over de leefkwaliteit van de buurt waarin hij of zij woont.

Minder dan 8 procent van de Vlaamse bevolking is niet of helemaal niet tevreden. Het feit echter dat 14 procent hun vrienden en kennissen niet

Tabel 1: Algemeen overzicht van de hinderpercentages voor de drie thema's

\begin{tabular}{|l|l|l|l|l||l|l|l|}
\hline & & $\begin{array}{l}\text { Helemaal niet } \\
\text { gehinderd } \%\end{array}$ & $\begin{array}{l}\text { Een beetje } \\
\text { gehinderd }\end{array}$ & $\begin{array}{l}\text { Tamelijk } \\
\text { gehinderd }\end{array}$ & $\begin{array}{l}\text { Tamelijk } \\
\text { gehinderd }\end{array}$ & $\begin{array}{l}\text { Ernstig } \\
\text { gehinderd }\end{array}$ \\
\hline Geluid & SLO0 & 35,1 & 33,9 & 19,3 & 9,1 & 2,3 & 30,7 \\
\hline & SLO1 & 32,7 & 37,8 & 17,7 & 9,9 & 1,9 & 29,5 \\
\hline & SLO2 & 37,6 & 35,4 & 16,8 & 8,2 & 2,0 & 27,0 \\
\hline Geur & SLOO & 54,1 & 27,0 & 11,7 & 5,6 & 1,4 & 1,1 \\
\hline & SLO1 & 55,5 & 29,1 & 10,2 & 4,1 & 4,7 & 15,4 \\
\hline & SLO2 & 57,0 & 27,7 & 9,8 & 1,3 & 15,3 \\
\hline Licht & SLO0 & 84,8 & 10,0 & 3,6 & 1,3 & 0,3 & 5,2 \\
\hline & SLO1 & 86,6 & 9,3 & 2,7 & 1,0 & 0,4 & 4,1 \\
\hline
\end{tabular}


Tabel 2: Evolutie van de hinderpercentages in Nederland versus Vlaanderen

Geluidshinder van

\begin{tabular}{|l|l|l|}
\hline Wegverkeer (NL)/Straatverkeer (VL) & 29,34 & 30,25 \\
\hline Railverkeer (NL)/Treinverkeer (VL) & 7,6 & 4,3 \\
\hline Vliegverkeer (NL)/Luchtvaart (VL) & 19,17 & 9,6 \\
\hline Industrie (NL)/Bedrijven, fabrieken (VL) & 4,3 & 5,4 \\
\hline Buren & 20,21 & 14,16 \\
\hline & & \\
\hline Geurhinder van & 7,7 & 14,12 \\
\hline Verkeer (NL)/Straatverkeer (VL) & 10,8 & 9,7 \\
\hline Industrie & 11,10 & $6>6$ \\
\hline Landbouw (NL)/Land- en tuinbouw (VL) & 9,12 & n.v.t.) 6 \\
\hline $\begin{array}{l}\text { Open haarden en/of allesbranders/Schoor- } \\
\text { steenafvoer van particulieren (VL) }\end{array}$ & & \\
\hline * Afgeronde cijfers & & \\
\hline
\end{tabular}

zou aanraden om in hun omgeving te komen wonen, nuanceert dit percentage enigszins. Het verkeer in al zijn aspecten is hiervoor zeer vaak een belangrijke reden.

Zoals uit tabel 1 blijkt, voelen de inwoners van Vlaanderen zich voornamelijk gehinderd door geluid, daarna door geur en tenslotte door licht. Bekijkt men de kolom 'minstens tamelijk gehinderd', dan valt het op dat het aantal Vlamingen die geluids- en geurhinder ondervinden, tussen 2000 en 2007 langzaam afneemt. Dit in tegenstelling tot lichthinder, waar ondanks een tijdelijke daling een netto toename van het aantal 'gehinderden' kan worden vastgesteld.

\section{Verschillen in hinder: geluidshinder, lichthinder en geur- hinder}

Uit het laatste SLO bleek dat 27 procent van de ondervraagden zich minstens tamelijk gehinderd voelt door geluid. lets meer dan 10 procent van de ondervraagden noemt de hinder zelfs ernstig of extreem. Dit percentage kan grotendeels worden herleid tot het ernstig of extreem gehinderd zijn door verkeer en vervoer (13 procent). Minder vaak vermeld als bron van wrevel zijn de buren (6 procent) en de industrie (4 procent). En hoewel activiteiten binnen de recreatieve en toeristische sfeer slechts door 5 procent van de Vlamingen worden genoemd, blijkt vooral crossen en racen meer en meer voor overlast te zorgen.

\section{Inwoners van Vlaanderen voelen zich gehinderd door geluid, geur en licht.}

Ongeveer één op de drie Vlamingen zegt bovendien soms of regelmatig wakker te worden door geluid. Straatverkeer is opnieuw de belangrijkste boosdoener, hoewel ook burenlawaai de nachtrust kan verstoren. Slaapverstoring door treinverkeer of luchtvaart komt eerder lokaal voor.

Figuur 1 illustreert dat geluidshinder door verkeer en vervoer in heel Vlaanderen voorkomt, met uitzondering van enkele dunbevolkte regio's zoals de Westhoek en de Noorderkempen. In de omgeving van de driehoek Antwerpen, Gent en Brussel blijkt de problematiek van verkeerslawaai wel heel duidelijk aanwezig te zijn, wat uiteraard niet hoeft te verwonderen gezien de belangrijke verkeersaders die zich daar situeren.

SLO2 geeft aan dat ernstige of extreme geurhinder op de eerste plaats veroorzaakt wordt door de buren en het verkeer (beiden 4,5 procent), gevolgd door de categorieën $\mathrm{KMO}$ en industrie (2,4 procent), water en zuivering (1,9 procent), en land- en tuinbouw (1,7 procent). In vergelijking met de vorige metingen blijkt dat vooral de buren steeds vaker de oorzaak zijn van geuroverlast, voornamelijk door schoorsteenafvoeren en het verbranden van afval in de open lucht. Binnen de categorie verkeer en vervoer, waar het aantal mensen dat zich gehinderd voelt in het algemeen opnieuw naar het oude niveau van 2000 is geëvolueerd, valt een significante stijging op van het percentage geuroverlast door de luchtvaart. De doelgroep KMO en industrie vertoont een lichte maar niet significante daling in ten opzichte van de situatie in 2003. Een uitzondering hierop zijn de mestverwerkingsbedrijven, waar een significante stijging werd geconstateerd.

In figuur 2 zijn de respondenten aangeduid die geurhinder ondervinden van één of meerdere ondernemingen. Deze figuur laat toe enkele hot spots te lokaliseren. Algemeen gaat het hier om stedelijke concentraties (bijvoorbeeld de Antwerpse binnenstad) en concentraties rond of langs belangrijke verkeersaders en knooppunten (bijvoorbeeld de havengebieden, de Brusselse noordrand en de zone in en rond Heusden-Zolder, Hasselt en Genk). In de rest van Vlaanderen vinden we her en der bronnen van geurhinder terug.

Lichthinder (bijvoorbeeld straatverlichting, lichtreclame en gebouwenverlichting) is een minder uitgesproken zij het niet verwaarloosbare oorzaak van een negatieve beleving van de woonomgeving. Gezien de lage hinderpercentages (steeds onder de 5 procent) is het moeilijk om op niveau van de specifieke bronnen statistisch relevante evoluties aan te tonen. Enkel voor skytracers en hemelprojectoren is er een duidelijke stijging van de ernstige en extreme lichthinder, hoewel het over zeer lage percentages gaat (van 0,1 naar 0,3 procent).

Figuur 3 geeft een totaalbeeld van de lichthinder in Vlaanderen. 


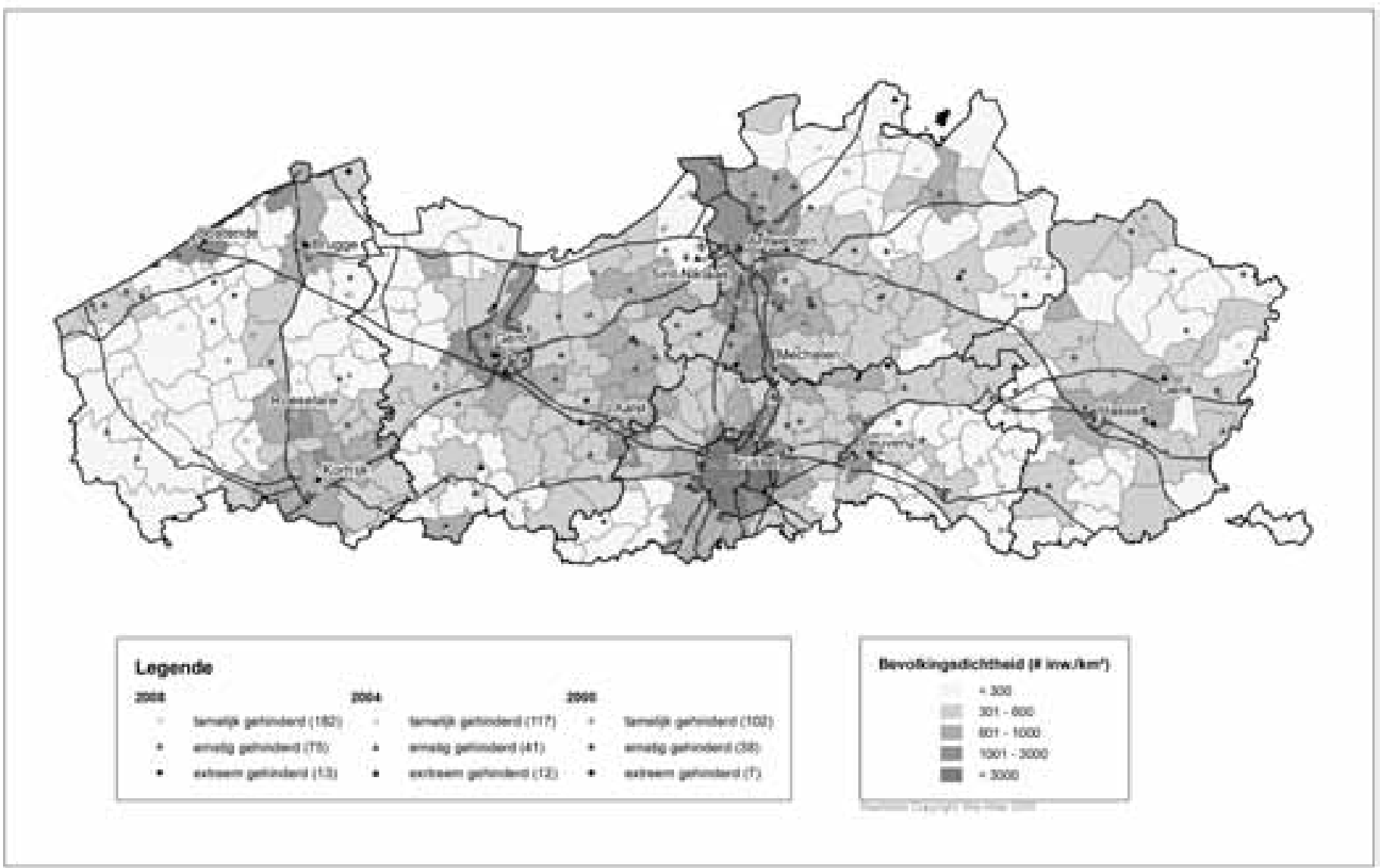

Geurhinder in Vlaanderen door KMO en industrie
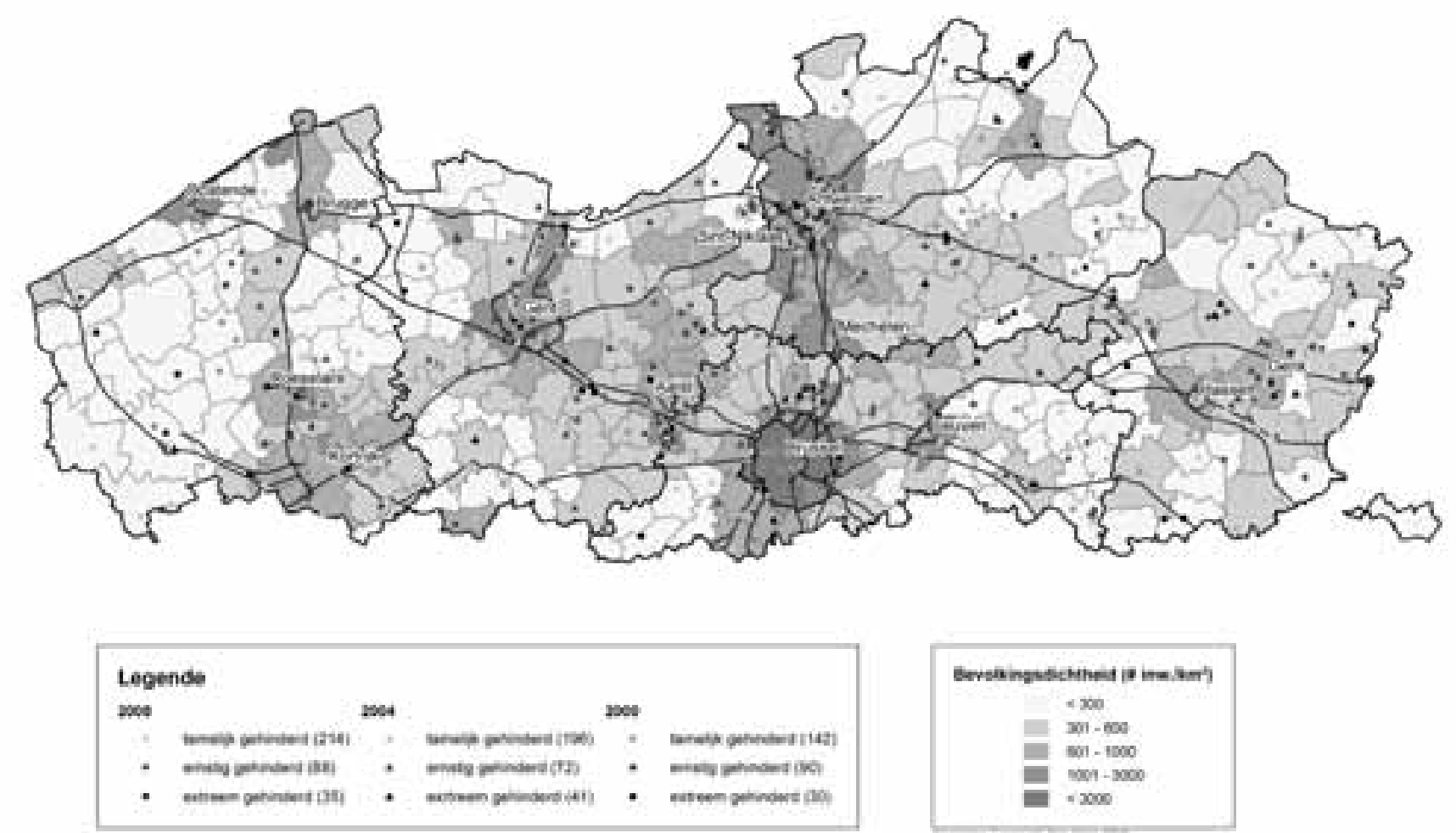


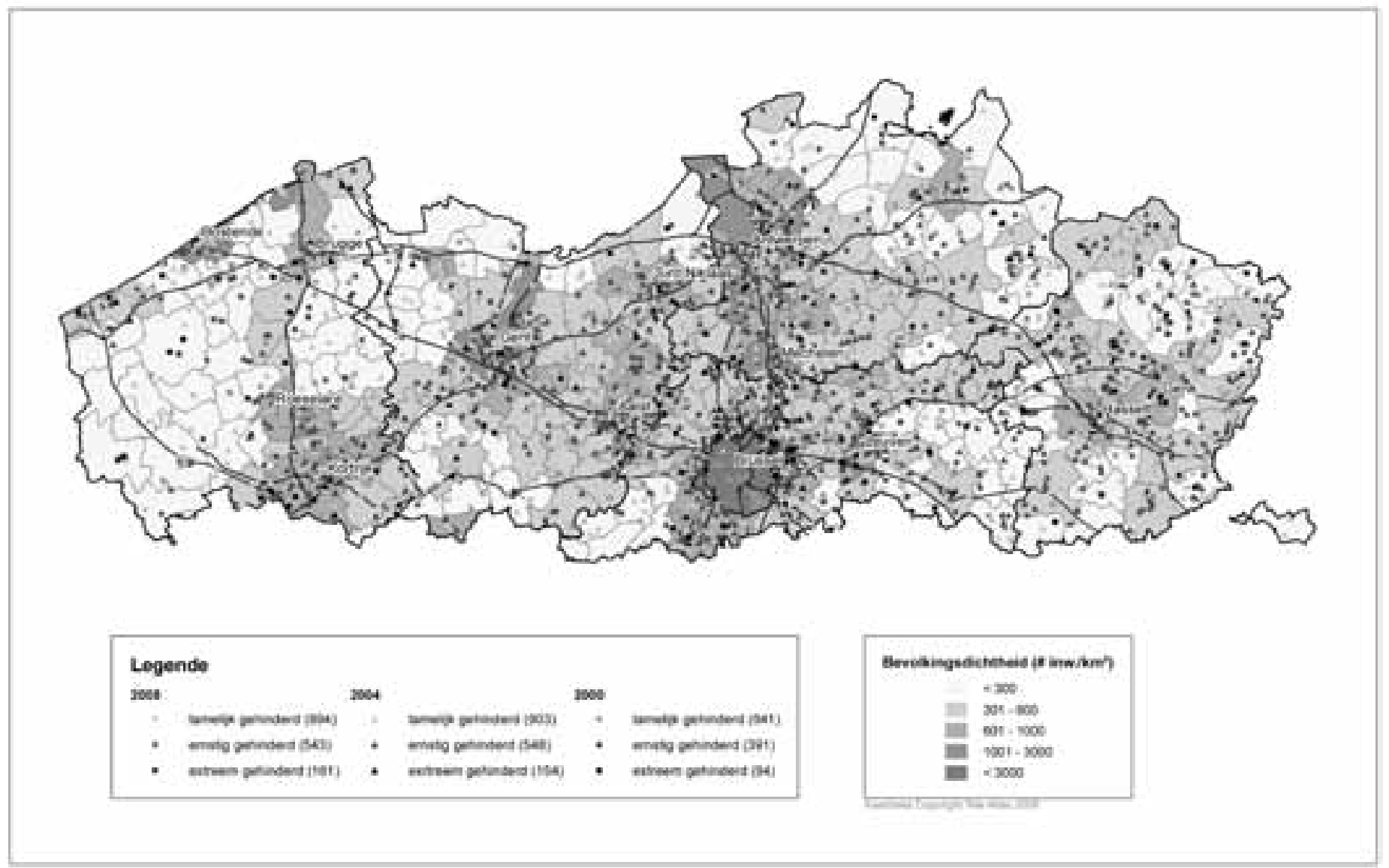

Opvallend is dat dit fenomeen opnieuw ruimtelijk sterk gecorreleerd is met enerzijds de bevolkingsdichtheid en anderzijds de belangrijke verkeerswegen.

Wanneer de Vlaming honderd euro belastingsgeld vrij kan verdelen over een vijftal beleidsmaatregelen, blijkt uit de enquête van 2008 dat hij een aanzienlijk deel van dit budget (35 euro) toewijst aan maatregelen ter vermindering van de luchtverontreiniging die wordt veroorzaakt door verkeer en vervoer. Twintig euro kent hij toe aan maatregelen ter vermindering van het lawaai van verkeer en vervoer. Maatregelen ter bestrijding van het overmatig verbruik van chemische bestrijdingsmiddelen in de landbouw krijgen achttien euro toebedeeld en maatregelen om de stank veroorzaakt door de industrie aan te pakken nog ruim vijftien euro. De stank van de landbouw wordt minder als een bedreiging aanzien, want dit krijgt 'slechts' zes van de honderd euro te verdelen belastingsgeld toegewezen.

\section{Is het beter wonen in Nederland?}

De uitgangssituatie in Nederland is min of meer dezelfde (een economisch ontwikkelde en dichtbevolkte regio), maar toch lijkt Nederland erin geslaagd iets meer orde te scheppen in de ruimtelijkeordeningssituatie. Omwille van een verschillende methodologie kunnen de cijfers uit de Nederlandse onderzoeken niet zomaar naast de Vlaamse cijfers worden gelegd. Toch doen we hier een poging om opmerkelijke gelijkenissen en verschillen te duiden (zie tabel 2). De Nederlandse cijfers zijn afkomstig van het Permanent Onderzoek Leefsituatie (POLS) en worden gepubliceerd door het Centraal Bureau voor de Statistiek
(CBS).

Uit deze cijfers blijkt dat meer dan acht op de tien Nederlanders tevreden tot zeer tevreden is met zijn of haar woonomgeving, waar dit in Vlaanderen 'slechts' zeven op de tien is. Dit kan duiden op een lagere tevredenheid over de milieukwaliteit door Vlamingen, maar is niet noodzakelijkerwijze het geval. Naast de milieukwaliteit beïnvloeden immers nog een heleboel andere fysieke en sociale aspecten de tevredenheid over de woonomgeving.

Het POLS peilt eveneens de geluids- en geurhinder. Voor de problematiek van lichthinder is niet meteen vergelijkbaar cijfermateriaal voorhanden. In Nederland is de voorbije jaren de geluidshinder van het wegverkeer gestegen, terwijl in Vlaanderen een daling is vastgesteld. Voor de overige categorieën worden in beide regio's dezelfde tendensen teruggevonden: geluidshinder door luchtverkeer, industrie en spoorverkeer neemt lichtjes af en burenoverlast neemt lichtjes toe. Het percentage geluidshinder door luchtverkeer is in Nederland echter opvallend hoger. Vlaanderen lijkt dan weer veel gevoeliger te zijn voor geurhinder van verkeer. De stank van de industrie daalde zowel in

\section{Nederland lijkt erin geslaagd iets meer orde te scheppen in de ruimtelijkeordenings- situatie.}


Nederland als in Vlaanderen, hoewel de daling volgens de cijfers van het CBS in Nederland betekenisvoller is (van 11 procent in 1997 tot 6 procent in 2008). Hier lijkt het 'geurbeleid', dat in Nederland al in de jaren tachtig is ingezet, zijn vruchten af te werpen. Ook de aanpak van de landbouw op het vlak van geurhinder lijkt intussen lonend te zijn, gelet op de daling van 14 procent naar 9 procent in twaalf jaar tijd. De stankoverlast van open haarden en kachels lijkt in Nederland over de voorbije jaren licht te stijgen tot ongeveer 11 à 12 procent. Vlaamse cijfers zijn nog onvolledig wat deze bron van geurwrevel betreft, maar alle signalen wijzen erop dat ook hier de komende jaren een toename zal vastgesteld worden.

De verschillen in beleving van de Nederlandse en Vlaamse woonomgeving zijn relatief klein. Beide regio's hebben te kampen met min of meer dezelfde problematiek en ondergaan dezelfde evoluties. Dit komt duidelijk tot uiting in de enquêtes die in beide landen werden gehouden. Hoewel zowel in Nederland als in Vlaanderen een beleid wordt gevoerd om lawaaioverlast, stank en de overmaat aan kunstmatig licht te beheersen, lijkt dit niet voor alle categorieën van activiteiten te lukken. De nodige waakzaamheid en daadkracht blijft zeker geboden om nieuwe knelpunten aan te pakken en negatieve tendensen om te buigen. Voor de problematiek van geluidshinder is de EU-richtlijn omgevingslawaai een belangrijke stimulans om een sterk beleid te kunnen voeren. Voor de problematiek van geurhinder en lichtvervuiling waar vanuit Europa nog geen aansturing gebeurt, zijn media-aandacht en waakzaamheid van de burger de voornaamste stimuli.

Gunther Van Broeck werkt bij de Vlaamse overheid, departement Leefmilieu, Natuur en Energie - afdeling Lucht, Hinder, Risicobeheer, Milieu \& Gezondheid (gunther.vanbroeck@Ine. vlaanderen.be)

\section{Literatuurselectie}

Deloitte \& Touche (2001). Schriftelijk Leefomgevingsonderzoek: Referentiemeting begin 2001. Onderzoek uitgevoerd in opdracht van de Vlaamse minister, bevoegd voor leefmilieu.

M.A.S. (2004). Uitvoeren van een schriftelijke enquête ter bepaling van het percentage gehinderden door geur, geluid en licht in Vlaanderen - SLO-1 meting. Onderzoek uitgevoerd in opdracht van de Vlaamse minister, bevoegd voor leefmilieu.

Planbureau voor de Leefomgeving (2009). Milieubelans 2009. PBL-publicatienummer 500081015.

Significant GfK (2008). Uitvoeren van een schriftelijke enquête ter bepaling van het percentage gehinderden door geur, geluid en licht in Vlaanderen - SLO-2 meting. Onderzoek uitgevoerd in opdracht van de Vlaamse minister, bevoegd voor leefmilieu.

Studiedienst van de Vlaamse Regering (2009). Beleving van geluidshinder in Vlaanderen. SVR -Rapport 2009/2 